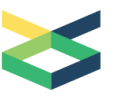

\title{
Feasibility of a Nutrition and Lifestyle Focused Shared Medical Appointment Program in a Resource-Challenged Community Setting
}

Nazleen Bharmal ( $\sim$ Nazleen.Bharmal@gmail.com )

Cleveland Clinic https://orcid.org/0000-0003-0663-2140

Michelle Beidelschies

Cleveland Clinic Health System: Cleveland Clinic

Marilyn Alejandro-Rodriguez

Cleveland Clinic Health System: Cleveland Clinic

Kayla Alejandro

Cleveland Clinic Health System: Cleveland Clinic

Ning Guo

Cleveland Clinic Health System: Cleveland Clinic

\section{Tawny Jones}

Cleveland Clinic Health System: Cleveland Clinic

\section{Elizabeth Bradley}

Cleveland Clinic Health System: Cleveland Clinic

\section{Research article}

Keywords: Shared medical appointments, Lifestyle intervention, Dietary intervention, Low-income participants, Disparities

Posted Date: February 26th, 2021

DOl: https://doi.org/10.21203/rs.3.rs-273932/v1

License: (a) (1) This work is licensed under a Creative Commons Attribution 4.0 International License. Read Full License 


\section{Abstract}

Background: In order to address disparities in preventable chronic diseases, we adapted a nutrition and lifestyle focused shared medical appointment (SMA) program to be delivered in an underserved community setting. The objective was to determine the feasibility of the community-based SMA pilot.

Methods: The SMA program was a community benefit for community residents regardless of their participation in the research study. We evaluated pre-post changes in wellness indices, biometrics, selfefficacy, and trust in medical researchers. To understand the barriers and facilitators for implementation and scalability, we conducted two participant focus groups and five stakeholder interviews and used content analysis to determine major themes.

Key Results: Fifteen participants attended 10 weekly sessions. The majority were older adult, African American women. There were pre-post improvements in mean systolic $(-10.5[7.7] \mathrm{mmHg}, p=0.0001)$ and diastolic $(-4.7$ [6.7] $\mathrm{mmgHg}, p=0.17)$ blood pressures and weight $(-5.7$ [6.3] pounds, $p=0.0034)$ at 3 months though these were not significant at 6 months. More individuals reported improvements in health status, daily fruit and vegetable intake, and sleep than at baseline. There were no significant pre-post changes in other wellness indices, self-efficacy, trust in medical researchers, hemoglobin A1c, insulin, or LDL cholesterol. Participants discussed positive health changes as a result of the SMA program, program preferences, and facilitators and barriers to continuing program recommendations in focus groups. SMA implementation was facilitated by clinical staff who adjusted content to a low health literacy group and partnership with a trusted community partner. Sustainability barriers include heavy personnel time and inkind resources to deliver the program.

Conclusion: Lifestyle-focused community-based SMAs can be a feasible and acceptable intervention for patients with neighborhood disadvantage, especially in partnership with trusted organizations.

\section{Background}

African Americans and/or individuals of lower socioeconomic status have a disproportionate burden of nutrition-related chronic diseases, such as obesity, high blood pressure, and diabetes $(1,2)$. This difference is partially due to neighborhood factors, such as living in resource-challenged environments with few outlets for affordable nutritious food, safe places for physical activity, and healthcare facilities $(3-5)$.

Shared medical appointments (SMA), or group appointments often led by multidisciplinary teams, are efficacious in delivering patient-centered care to individuals with chronic conditions (6-8). A narrative review found group visits for low-income and underserved populations to be effective in diabetic preventive care; however, most studies were in clinical settings (9). Few studies have examined the impact of delivering SMAs in communities with neighborhood disadvantage. 
In 2017, the Center for Functional Medicine launched a SMA program to promote positive nutrition and lifestyle-related behaviors in order to address various chronic conditions. Briefly, this 10-week SMA leverages a multi-disciplinary team to provide education related to nutrition, lifestyle and behavioral health recommendations. Providers deliver education and care in a shared setting plus a brief, individual medical assessment. Health coaches provide education related to exercise and movement, sleep, stress reduction and tools to support lasting behavioral change. Dieticians focus on the use of food as medicine, and support participants in the implementation food plan that encourages consumption of whole, unprocessed foods. By the end, participants are empowered to make positive decisions regarding food and become advocates within their homes and communities.

In partnership with healthcare system-based community engagement staff, the Center for Functional Medicine designed a community-based SMA program for community residents living in a resourcechallenged Cleveland neighborhood. Our objective was to determine the feasibility and acceptability of the pilot SMA program delivered in a community setting through participant focus groups and stakeholder interviews. We also evaluated pre-post changes in wellness indices, biometrics, self-efficacy, and trust in medical researchers.

\section{Methods}

\section{Community-Based SMA Program}

The community-based SMA program was offered as a community benefit and adapted from the clinically-based SMA program (10). Briefly, the community-based SMA program focused on weight management utilizing a cardiometabolic food plan similar to the Mediterranean Diet (11). It consisted of weekly, in-person group sessions with four sessions led by a clinical practitioner (PA-C) and health coach, and six sessions led by a registered dietician. Each session lasted for 1-2 hours.

Sessions were held at the Langston Hughes Community Health and Education Center in the Fairfax neighborhood of Cleveland, Ohio which is staffed by Cleveland Clinic Community Relations staff and includes a free community gym and health education rooms. Fairfax is home to over 6,000 residents with $94 \%$ identifying as Black or African American and $62 \%$ having a high school diploma or less educational attainment (12). The majority of households are in or near poverty which is a result of years of redlining, disinvestment, and population decline (12). Residents within the Fairfax neighborhood suffer from a number of health disparities compounded by social determinants of health, such as higher rates of heart disease, cancer, diabetes, and kidney disease than the surrounding areas.

The SMA visits delivered nutrition and lifestyle-related education, provided participants with educational tools, and fostered open discussion. Community residents were provided customized shopping lists for cooking and menu options for eating out. A cooking demonstration session helped residents appreciate how to prepare certain foods. As part of the SMA, community residents received in-kind laboratory testing, 
dietary supplementation (Pure Lean Pure Pack and Vitamin D (Pure Encapsulations, LLC)), and weekly food delivery (Freshly, Inc.) for themselves and three additional members of their household.

\section{Study Population and Design}

The study population consisted of two groups - SMA participants and programmatic stakeholders. Community residents of the Fairfax neighborhood were selected to participate in the community-based SMA program regardless of whether they chose to participate in the study. However, selection for the SMA program was limited to residents who had participated in prior health challenges conducted by the Community Relations team. After obtaining written informed consent, study participants were asked to complete written surveys pre- and post-SMA, biometric measurements at three time intervals, and two focus groups.

Programmatic stakeholders $(n=5)$ were those who provided administrative support and/or delivered the program. After providing written consent, they completed interviews focused on the implementation and dissemination of the SMA program.

The pre-post design community-based pilot study was approved by the Cleveland Clinic Institutional Review Board and conducted from September 2019-February 2020. The study design, survey instruments, focus group guides, and stakeholder interview questions were reviewed by the Community Relations staff to ensure cultural competency.

\section{Survey and Biometrics}

SMA participants completed a written survey at baseline and 3 months (post-SMA). Survey items included demographic information and validated instruments on wellness indices (13), food security (14), self-efficacy $(15)$, and trust in medical research $(16,17)$, and SMA program experience. Wellness indices included self-reported health status, fruit/vegetable intake, physical activity, sleep duration, stress levels, alcohol and tobacco use. Survey responses on food security, self-efficacy, and trust in medical research were on a 5-point Likert scale of from strongly disagree to strongly agree. Participants received \$10 for each survey completion.

Weight and blood pressure were assessed at baseline, 3 months, and 6 months. Laboratory testing for hemoglobin A1c (HbA1c), fasting insulin and low-density lipoprotein (LDL) cholesterol levels was evaluated at baseline and 3 months.

\section{Focus Groups and Stakeholder Interviews}

Two, 60-minute focus groups were conducted with SMA participants and facilitated by the principal investigator $(\mathrm{PI})$. The first focus group was conducted one week after the completion of the 10-week community-based SMA program. Residents were asked to discuss their experiences in the program. The second focus group was conducted three months following the completion of the community-based SMA program. Residents were asked to discuss factors influencing the maintenance of positive health-related behaviors. Study participants received a \$30 incentive for participation in each focus group. 
The PI conducted one-on-one, 60-minute stakeholder interviews using a semi-structure survey. Interviews aimed to determine general and site-specific factors associated with greater effectiveness, and to assess the feasibility, acceptability, and sustainability of the community-based SMA program. Interview questions were guided by previous successful implementation analyses and asked the following: What are the organizational resources to carry out the intervention? What are the staff experience and capacity to carry out the intervention? What are the potential barriers and facilitators to implementing the intervention? What potential modification to the intervention would need to be made to maximize implementation? (18).

Focus groups and stakeholder interviews were recorded by audio-tape and through researchers' notes.

\section{Statistical Analysis}

We described baseline characteristics for community-based SMA participants. Pre- and post-SMA biometrics and self-reported survey items were compared using paired t-test, McNemar's test, or Fisher's exact test. Mean scores for general self-efficacy were assessed (8-items, range 8-40) with higher scores representing greater perceived self-efficacy. Mean scores for trust were assessed (5-items, range 5-25) with higher scores representing greater trust in medical researchers. Statistical analyses were conducted using SAS version 9.4 (SAS Institute, Inc. Cary, NC). Statistical significance was established at $p<0.05$. Results were shared in aggregate with the community partners and study participants.

Transcribed audio-taped sessions of focus groups were read by at least three research-eligible staff who used content analysis methods to identify and discuss main themes (kappa $=0.70$ for inter-rater reliability). Stakeholder interviews were read by the PI and analyzed for main themes associated with the implementation and sustainability of the community-based SMA program.

\section{Results}

Fifteen community residents participated in the community-based SMA program; all chose to participate in the research study. The majority of participants were older adult, African American women (Table 1). Half the participants reported living with high blood pressure, one-third with diabetes, and one-fifth with sleep apnea. Most reported having health insurance and a primary care doctor. While almost all the participants reported feeling confident in meal preparation with vegetables, there were varied responses to healthful food availability and food security. All participants attended the 10 weekly sessions of the SMA program, which was facilitated by the Community Relations staff providing phone call reminders. One participant died about 2 months after program completion. 
Table 1

Characteristics of community-based SMA program participants $(n=15)$

n (\%)

Sex

Female 13

Male

Age

$18-40$ years

$0(0.0)$

$41-64$ years

$7(46.7)$

65-80 years old

$8(53.3)$

Race/Ethnicity*

African-American/Black

Caucasian/White

\section{Educational attainment}

$<$ High school graduate

$0(0.0)$

HS diploma, GED

Vocational school or some college

College or higher

Chronic conditions

High Blood Pressure

Diabetes

Sleep Apnea

Health insurance*

Yes

No

$0(0.0)$

\section{Primary Care Provider*}

*Missing $=1$ 


\begin{tabular}{|l|l|}
\hline & $\mathrm{n}(\%)$ \\
\hline Yes & 14 \\
\hline No & $03.3)$ \\
\hline Feel confident in knowing how to prepare fresh vegetables for meals & \\
\hline Strongly agree/agree & 14 \\
\hline Strongly disagree/disagree & $(93.3)$ \\
\hline Neutral & 0 \\
\hline Easy to buy fresh fruits and vegetables in my neighborhood & $1(6.7)$ \\
\hline Strongly agree/agree & $8(53.3)$ \\
\hline Strongly disagree/disagree & $1(6.7)$ \\
\hline Neutral & $6(40.0)$ \\
\hline $\begin{array}{l}\text { Within the past 30 days, we worried whether our food would run out before we got money } \\
\text { to buy more }\end{array}$ & \\
\hline Strongly agree/agree & $3(20.0)$ \\
\hline Strongly disagree/disagree & $4(26.7)$ \\
\hline Neutral & $8(53.3)$ \\
\hline $\begin{array}{l}\text { Within the past 30 days, the food we bought just didn't last and we didn't have money to } \\
\text { get more }\end{array}$ & \\
\hline Strongly agree/agree & $2(13.3)$ \\
\hline Strongly disagree/disagree & 10 \\
\hline Neutral & $3(20.0)$ \\
\hline *Missing = & \\
\hline
\end{tabular}

Table 2 reports change in self-reported wellness indices at 3 months. Four participants moved from fair or poor health status to good health status. More participants reported increased food and vegetable intake and sleep following completion of the program; however, these did not reach statistical significance.

There was no change in physical activity or stress level. None of the participants reported heavy alcohol use or smoking. There was no significant change in perceived self-efficacy (mean score pre-SMA 31.7 and post-SMA 32.8 out of 40) or trust in medical researchers (pre-SMA 20, post-SMA 20.4 out of 25) with relatively high baseline scores for both scales. 
Table 2

Change in self-reported wellness indices for community-based SMA program participants

No. (\%)

$\begin{array}{lllll} & \text { N } & \text { Baseline } & \text { 3 months } & \text { P-value }^{\dagger} \\ \text { Health Status } & 15 & 2(13.3) & 2(13.3) & 0.19 \\ \text { Excellent or very good } & & 9(60.0) & 13(86.7) & \\ \text { Good } & & 4(26.7) & 0(0) & \end{array}$

Fair or poor

Fruits and Vegetable Intake*

$126(50.0)$

$10(83.3)$

0.22

5 or more servings/day

Physical activity*

$14 \quad 14(100.0)$

$13(86.7)$

$\mathrm{n} / \mathrm{a}$

More than $150 \mathrm{~min} /$ week

Sleep

7 or more hours/night

Stress

Rarely or Sometimes

Alcohol consumption

Less than 7 drinks/week (women) or

14 drinks/week (men)

Tobacco Use

$15 \quad 15(100.0)$

$15(100.0)$

n/a

No

*Data not available for all subjects. Missing values: Fruits and Vegetable Intake $=3$; Physical Activity $=1$

${ }^{\dagger} \mathrm{P}-\mathrm{V}$ alue for the change from baseline to 3 months

We found significant change in mean weight and blood pressure (Table 3). At 3 months, participants had a significant improvement in their mean weight $(-5.7$ [6.3] pounds, $p=0.0034)$, and systolic $(-10.5[7.7]$ $\mathrm{mmHg}, \mathrm{p}=0.0001)$ and diastolic $(-4.7$ [6.7] $\mathrm{mmHg}, \mathrm{p}=0.017)$ blood pressures. Weight and blood pressure were available at 6 months for a subset of community-SMA participants and while there were improvements, they did not reach statistical significance. There was no significant change in mean $\mathrm{HbA1c}$, total insulin or LDL cholesterol levels at 3 months. 
Table 3

Change in biometrics for community-based SMA program participants

\begin{tabular}{|c|c|c|c|c|c|c|c|c|}
\hline & \multicolumn{4}{|c|}{ Mean (SD) } & \multicolumn{4}{|c|}{ Mean (SD) } \\
\hline & Baseline & $\begin{array}{l}3 \\
\text { months }\end{array}$ & Change* & $\begin{array}{l}\mathrm{P} \text { - } \\
\text { Value }\end{array}$ & Baseline & $\begin{array}{l}6 \\
\text { months }\end{array}$ & Change* & $\begin{array}{l}\text { P- } \\
\text { Value }\end{array}$ \\
\hline $\mathbf{N}$ & 15 & 15 & & & 8 & 8 & & \\
\hline Weight, lbs. & $\begin{array}{l}225.9 \\
(59.7)\end{array}$ & $\begin{array}{l}220.1 \\
(56.6)\end{array}$ & $\begin{array}{l}-5.7 \\
(6.3)\end{array}$ & 0.0034 & $\begin{array}{l}195.9 \\
(49.3)\end{array}$ & $\begin{array}{l}193.1 \\
(50.9)\end{array}$ & $\begin{array}{l}-2.8 \\
(7.2)\end{array}$ & 0.30 \\
\hline $\begin{array}{l}\text { Systolic } \\
\text { Blood } \\
\text { Pressure, } \\
\mathrm{mm} / \mathrm{Hg}\end{array}$ & $\begin{array}{l}132.2 \\
(9.3)\end{array}$ & $\begin{array}{l}121.7 \\
(8.0)\end{array}$ & $\begin{array}{l}-10.5 \\
(7.7)\end{array}$ & 0.0001 & $\begin{array}{l}132.6 \\
(9.3)\end{array}$ & $\begin{array}{l}126.9 \\
(8.4)\end{array}$ & $\begin{array}{l}-5.8 \\
(10.0)\end{array}$ & 0.15 \\
\hline $\begin{array}{l}\text { Diastolic } \\
\text { Blood } \\
\text { Pressure, } \\
\mathrm{mm} / \mathrm{Hg}\end{array}$ & $\begin{array}{l}65.3 \\
(8.9)\end{array}$ & $\begin{array}{l}60.6 \\
(10.6)\end{array}$ & $\begin{array}{l}-4.7 \\
(6.7)\end{array}$ & 0.017 & $\begin{array}{l}62.9 \\
(7.3)\end{array}$ & $\begin{array}{l}64.1 \\
(9.3)\end{array}$ & $1.3(7.6)$ & 0.66 \\
\hline HbA1c, \% & $\begin{array}{l}6.1 \\
(0.50)\end{array}$ & $\begin{array}{l}6.2 \\
(0.56)\end{array}$ & $\begin{array}{l}0.11 \\
(0.34)\end{array}$ & 0.052 & $\mathrm{n} / \mathrm{a}$ & $\mathrm{n} / \mathrm{a}$ & $\mathrm{n} / \mathrm{a}$ & $n / a$ \\
\hline $\begin{array}{l}\text { Insulin, } \\
\mathrm{mU} / \mathrm{L}\end{array}$ & $\begin{array}{l}13.2 \\
(8.1)\end{array}$ & $\begin{array}{l}11.6 \\
(8.0)\end{array}$ & $\begin{array}{l}-1.6 \\
(3.7)\end{array}$ & 0.11 & $\mathrm{n} / \mathrm{a}$ & $n / a$ & $\mathrm{n} / \mathrm{a}$ & $n / a$ \\
\hline $\begin{array}{l}\text { LDL, } \\
\text { Cholesterol, } \\
\mathrm{mg} / \mathrm{dL}\end{array}$ & $\begin{array}{l}105.5 \\
(36.8)\end{array}$ & $\begin{array}{l}108.5 \\
(40.0)\end{array}$ & $\begin{array}{l}3.1 \\
(11.4)\end{array}$ & 0.32 & $\mathrm{n} / \mathrm{a}$ & $n / a$ & $\mathrm{n} / \mathrm{a}$ & $n / a$ \\
\hline \multicolumn{9}{|c|}{ *For the change from baseline to 3 months, and baseline to 6 months. } \\
\hline Bold & & & & & & & & \\
\hline
\end{tabular}

\section{Participant Focus Group and Stakeholder Interview Themes}

All FFL Community study participants joined in the first focus group after the SMA program. The majority reported by survey that they did not have a hard time following the nutritional recommendations, incorporating the lifestyle changes, taking the supplements, and/or eating the food delivery meals of the SMA program. Themes were grouped into three categories: 1 ) education and health changes due to the SMA program; 2) program preferences; and, 3) thoughts about future state.

\section{Education and Health Changes}

Participants shared several health changes as a result of the community-based SMA program. These included a greater understanding of food as medicine and inflammatory foods, more water intake, improved gut function, more mindful eating practices, and improved energy levels. Participants discussed the connection between program activities and function: 
My thing is that it allows me to function, and function better. By eating the right foods, taking supplements, being mindful of what and when I eat. (Female participant)

Eat slowly. I ate so fast, they taught me to place fork down, and chew food thoroughly never used to chew, my food, and I'm enjoying the flavors in the food. (Female participant)

The routines help your body to feel better, more energy, I started jogging. (Female participant)

\section{Program Preferences}

Several factors influenced the uptake of the community-based SMA program recommendations. Participants appreciated the time for and method of explanation given for nutrition choices, test results, and use of dietary supplements. A few commented that this was different than their current experience with medical care.

\section{Most places don't explain why you shouldn't eat something, just to not eat it. (Female)}

I liked the cardio metabolic testing they did. If you were to go to your doctor, they wouldn't do that... [The SMA program staff] tell you what to focus on. No doctor has every mentioned that. (Female)

Community-based SMA participants appreciated the in-kind resources of meal delivery, dietary supplements, and laboratory testing. They especially liked the curriculum and delivery of the program, including the cooking demonstration session. The value of the group support was also discussed.

I like the way you focus on how's and whys, why you do something. The group support was a main reason. We supported each other on things. (Female)

Participants' preferences for changes to the program included more variety in food choices, even more individualized support, and more cooking demonstrations. Possible additions to the program included adding a physical activity component and ensuring an affordable program if supplements and food were not covered.

\section{Future state}

SMA participants had two main thoughts on next steps. The first was that they had received enough information to be in control of their health journey. The second was concern about continuing the habits without the group and the meal delivery/food component due to time and budget constraints. In response to the concerns, the Community Relations team provided health activities that would facilitate group members meeting and being accountable to their goals.

In learning what foods to eat to help blood pressure and cholesterol, we knew this, but being in group helped so much. I have been on millions of diets, and this is the first time I was able to lose weight, lower blood pressure, and cut my high blood pressure medicine. And now, I know where to go. (Female) 
The program is not a piece of cake, you have to get off the couch. We have done healthy challenges, so this part wasn't too difficult for us. But, with diet, it's very hard because you have to pass a bunch of fast food restaurants when you're getting from place to place, think about grabbing this grabbing that. You have to work at diet to stick with it. (Male)

A second focus group with eight participants was conducted 3 months after the completion of the community-based SMA program. All maintained several aspects of the program, including increased healthful food and water consumption. Barriers to maintenance stemmed from the loss of weekly sessions and the loss of prepared food (meal delivery) to support portion size and food choices.

Well one thing about being by myself, is that I don't cook that much. Like if I do cook something, and I cook a big amount, it is all gone. Those dinners helped me a lot with the portion. Then when I tried to figure out what was too much by using the palm of my hand, I realized I had two pieces of chicken. I really have to work on that. It's really hard. But the meals were helpful. (Female)

Facilitators for maintenance included preparing meals in advance, recalling learnings from the SMA program, receiving positive feedback on health, and sharing health education with family and friends.

I actually got a little lazier after the program because we were receiving the meals and we did not have to cook. It was really time saving. I ended up getting the meals again because I thought that was the easiest for me and the easiest way out. It isn't difficult though. This Sunday I cooked three different things that would last for the week. Which I could've been doing; saving that Sunday to do all the time but it was football season at the time. (Male)

When I went to the hairdresser, they told me that my hair got stronger and that there was more hair. (Female)

I went to my regular doctor and they told me that whatever I'm doing, I should keep doing. They said I am in excellent shape and to continue doing what l've been doing. (Female)

Table 4 illustrates key themes for implementation as discussed with SMA program stakeholders. Barriers to sustainability include heavy time and personnel resources to carry out the program and need to adapt the program to community participants with significant medical and socioeconomic needs. Facilitators to implementation included enthusiastic clinical staff who were familiar with the content and could adjust to a lower health literacy group than seen in clinically-based SMAs, partnership with a trusted community organization, and ability to obtain in-kind resources to support participants' full engagement in the program. 
Table 4

Stakeholder interviews findings on the implementation of community-based SMA program Implementation Questions Themes

What are the organizational resources to carry out the FFL Community program?
- Existing program adapted to community setting

- FTE support for multidisciplinary team - dietician, health coach, clinician, and administrative teams to deliver the program

- Ability to obtain in-kind donations for meal delivery, dietary supplements, laboratory testing, and printed health education material

- Existing community health activities and team that facilitated the selection of participants
What are the staff experience and capacity to carry out FFL Community?

- Significant clinical staff experience and passion to adapt the SMA program for a group with more health and socioeconomic needs than usual patients who may not have financial or environmental barriers

- Cultural competency and authenticity of providers

What are the potential barriers to implementing FFL Community?

- Significant time preparation for those that delivered the program content to meet participants' health literacy and morbidity level (e.g., most participants did not have computers or wifi access so all materials needed to be printed)

- Large group as there was no attrition among the participants

- Lack of space in community setting made one-on-one sessions challenging for physical exam or lab review

- Lack of staff knowledge about local community resources - unsure if enough tools provide for participants to continue program on their own given environment and health conditions

- Sustainability and scaling limited as program was resource intense and non-revenue generating; dependent on philanthropic support

- Distrust between community residents and healthcare system

What are the potential facilitators to implementing FFL Community?
- Ongoing communication and engagement between the clinical and community teams for planning, flexible execution, and evaluation

-Weekly reminder calls to participants from the community team

- Participants were familiar with each other, health activities, and the community site which facilitated group engagement

- Meal delivery facilitated nutrition; unclear if sustainable 


\begin{tabular}{|ll|}
\hline Implementation Questions & Themes \\
\hline $\begin{array}{ll}\text { What potential modification } \\
\text { to FFL Community would } \\
\text { need to be made to } \\
\text { maximize implementation? }\end{array}$ & $\begin{array}{l}\text { - Better understanding of community members' needs and assets to } \\
\text { adapt program content }\end{array}$ \\
& $\begin{array}{l}\text { - More experiential learning, such as cooking demonstrations and } \\
\text { grocery store shopping on food vouchers } \\
\text { - Develop and incorporate activities for longer support of participants }\end{array}$ \\
\hline
\end{tabular}

\section{Discussion}

The community-based, lifestyle-focused SMA program was feasible in a community setting for patients living in a resource-challenged neighborhood. Participants were able to incorporate lifestyle changes and had improvement in their mean weight and blood pressure over the course of the program. Focus group findings described health changes in energy, gut function, and overall function as a result of the SMA program among a group of individuals who were "bought-in" to healthful lifestyles given their prior participation in community health programs. At least half of participants were able to adapt to the loss of meal delivery and weekly group sessions to continue healthful practices at least 3 months post-SMA program.

These findings are important because they add to the body of scientific literature examining communitybased, collaborative interventions that may help to reduce the nutrition-related chronic disease burden in underserved communities (19-22). SMAs are attractive because they may facilitate social connection and support, disease self-management, and trust in medical professionals (8). As with other studies in community settings, partnership and engagement with trusted community organizations is needed from the outset. The acceptability of the community-based SMA program was in part due to a prior trust between participants and the Community Relations staff. The staff were supportive of the SMA program and helped facilitate participant attendance and program implementation. However, sustainability and scaling barriers include significant personnel time and need for philanthropic support (i.e., unknown if cost-effective) to deliver the SMA in low-income settings.

This study has several limitations. First, the overall design was a pre-post comparison study with no control group. Second, there was selection bias for participants chosen by the community team to participate in the SMA program. Specifically, participants were chosen based on their passion for health and wellness after successful completion of other healthy community programs. Therefore, study participants' likely had higher self-efficacy that contributed to greater adherence and session attendance than another group of residents. Third, the small sample size was small limits the generalizability of our findings. Lastly, many outcomes were self-reported, which may be exaggerated due to social desirability reporting bias. Regardless, the current study also included quantitative measures, though comparison pvalues may be significant by chance.

\section{Conclusions}


Community-based SMA programs focused on nutrition and lifestyle are feasible and acceptable approaches to address health disparities in chronic conditions. However, future studies are warranted to evaluate various factors including long-term program sustainability, community resident engagement, and the impact of improved health literacy. Additionally, examining the resource-effectiveness of community-based nutrition-focused SMA programs to underserved communities, especially in comparison with other modalities, such as medically-tailored meals or prescription food programs would be beneficial.

\section{Abbreviations}

SMA shared medical appointments

HbA1c hemoglobin A1c

LDL low-density lipoprotein

DECLARATIONS:

\section{Declarations}

Ethics approval: The pre-post design community-based pilot study was approved by the Cleveland Clinic Institutional Review Board and conducted from September 2019-February 2020. The study design, survey instruments, focus group guides, and stakeholder interview questions were reviewed by the Community Relations staff to ensure cultural competency.

Data Availability: The datasets generated and/or analyzed during the current study are not publicly available due confidential personal health information but are available from the corresponding author on reasonable request.

Competing interests: The authors declare that they have no competing interests

Funders: There was no external funding source for this study; all staff time was covered as part of Cleveland Clinic operations. There was philanthropic donations of dietary supplementation by Pure Encapsulations, LLC and weekly food delivery by Freshly, Inc.; of note, neither entity had a role in the study design, manuscript drafts, and/or in the collection, analysis, and interpretation of data.

\section{Authors' contributions:}

NB: conceptualized the study, designed the study, drafted the protocol and surveys, connected with the community partners, consented the participants, led the data analysis, interpreted the data, drafted the manuscript

MB: helped with survey design, focus group protocols, data analysis, and manuscript draft 
MAR: submitted to IRB, consented participants, helped with data collection and analysis

KA: helped with focus group protocols, qualitative data analysis

NG: analyzed the survey data and biometrics

TJ: helped with study design, supported the SMA program, acquired philanthropic support

EB: helped with study design, supported the SMA program

All authors read and approved the final manuscript.

Acknowledgements:

The authors would like to thank the Langston Hughes Community Center staff for their support on the study. The authors would like to thank past and present members of the Center for Functional Medicine team for their support on the study and dedication to delivering exceptional care to the community residents. We would also like to thank Michelle King for focus group transcription.

\section{References}

1. Cunningham TJ, Croft JB, Liu Y, Lu H, Eke PI, Giles WH. Vital Signs: Racial Disparities in Age-Specific Mortality Among Blacks or African Americans - United States, 1999-2015. MMWR Morb Mortal Wkly Rep. 2017;66(17):444-56.

2. National Center for Health Statistics. Health, United States: Socioeconomic status and health chartbook: US Department of Health and Human Services, Centers for Disease Control and Prevention; 1998.

3. Larson NI, Story MT, Nelson MC. Neighborhood environments: disparities in access to healthy foods in the U.S. Am J Prev Med. 2009;36(1):74-81.

4. Gordon-Larsen P, Nelson MC, Page P, Popkin BM. Inequality in the built environment underlies key health disparities in physical activity and obesity. Pediatrics. 2006;117(2):417-24.

5. Gaskin DJ, Thorpe RJ Jr, McGinty EE, Bower K, Rohde C, Young JH, et al. Disparities in diabetes: the nexus of race, poverty, and place. Am J Public Health. 2014;104(11):2147-55.

6. Housden L, Wong ST, Dawes M. Effectiveness of group medical visits for improving diabetes care: a systematic review and meta-analysis. Cmaj. 2013;185(13):E635-44.

7. Housden LM, Wong ST. Using Group Medical Visits With Those Who Have Diabetes: Examining the Evidence. Curr Diab Rep. 2016;16(12):134.

8. Kirsh SR, Aron DC, Johnson KD, Santurri LE, Stevenson LD, Jones KR, et al. A realist review of shared medical appointments: How, for whom, and under what circumstances do they work? BMC Health Serv Res. 2017;17(1):113. 
9. Vaughan EM, Johnston CA, Arlinghaus KR, Hyman DJ, Foreyt JP. A Narrative Review of Diabetes Group Visits in Low-Income and Underserved Settings. Curr Diabetes Rev. 2019;15(5):372-81.

10. Cleveland Clinic Center for Functional Medicine. Description of Functioning for Life Program [Available from: https://my.clevelandclinic.org/departments/functionalmedicine/programs/functioning-for-life-appointments.

11. Insitute for Functional Medicine. Cardiometabolic Food Plan 2016 [Available from: https://centerforfunctionalmedicine.com/wp-content/uploads/2016/10/Cardiometabolic-FoodPlan_v15-1.pdf.

12. Center for Community Solutions. Fairfax Neighborhood Factsheet: 2010-2014 ACS 5-Year Estimates for Cleveland neighborhoods were calculated by NODIS at Cleveland State University. 2016. Available at: https://www.communitysolutions.com/resources/community-fact-sheets/clevelandneighborhoods-and-wards/.

13. Centers for Disease Control and Prevention (CDC). Behavioral Risk Factor Surveillance System Survey Data. Atlanta: U.S. Department of Health and Human Services, Centers for Disease Control and Prevention; 2018.

14. Hager ER, Quigg AM, Black MM, Coleman SM, Heeren T, Rose-Jacobs R, et al. Development and validity of a 2-item screen to identify families at risk for food insecurity. Pediatrics. 2010;126(1):e2632.

15. Chen G, Gully SM, Eden D. Validation of a new general self-efficacy scale. Organizational research methods. 2001;4(1):62-83.

16. Corbie-Smith G, Thomas SB, St George DM. Distrust, race, and research. Arch Intern Med. 2002;162(21):2458-63.

17. Hall MA, Camacho F, Lawlor JS, Depuy V, Sugarman J, Weinfurt K. Measuring trust in medical researchers. Med Care. 2006;44(11):1048-53.

18. Curran GM, Bauer M, Mittman B, Pyne JM, Stetler C. Effectiveness-implementation hybrid designs: combining elements of clinical effectiveness and implementation research to enhance public health impact. Med Care. 2012;50(3):217-26.

19. Keyserling TC, Samuel-Hodge CD, Pitts SJ, Garcia BA, Johnston LF, Gizlice Z, et al. A communitybased lifestyle and weight loss intervention promoting a Mediterranean-style diet pattern evaluated in the stroke belt of North Carolina: the Heart Healthy Lenoir Project. BMC Public Health. 2016;16:732.

20. Blanks SH, Treadwell H, Bazzell A, Graves W, Osaji O, Dean J, et al. Community Engaged Lifestyle Modification Research: Engaging Diabetic and Prediabetic African American Women in CommunityBased Interventions. J Obes. 2016;2016:3609289.

21. Coughlin SS, Smith SA. Community-Based Participatory Research to Promote Healthy Diet and Nutrition and Prevent and Control Obesity Among African-Americans: a Literature Review. J Racial Ethn Health Disparities. 2017;4(2):259-68. 
22. Ferdinand DP, Nedunchezhian S, Ferdinand KC. Hypertension in African Americans: Advances in community outreach and public health approaches. Prog Cardiovasc Dis. 2020;63(1):40-5. 